\title{
ACESSIBILIDADE EM INFOGRAFIAS PARA SURDOS: SERÁ QUE OS SEGREDOS MAIS SECRETOS PERTENCEM AO MUNDO VISÍVEL?
}

\section{INFOGRAPHICS ACCESSIBILITY FOR DEAFS: WILL THE SECRET SECRETS BELONG TO THE VISIBLE WORLD?}

\author{
Mariana Lapolli ${ }^{1}$, Dra. \\ Tarcísio Vanzin ${ }^{2}$, Dr. \\ José Luis Valero Sancho ${ }^{3}$, Dr. \\ (1) Célia Helena Centro de Artes e Educação \\ e-mail: marilapolli@gmail.com \\ (2) Universidade Federal de Santa Catarina \\ e-mail:tvanzin@gmail.com \\ (3) Universidad Autónoma de Barcelona \\ e-mail: JoseLuis.Valero@uab.cat
}

Infografia, Surdo, Acessibilidade

Este artigo trata da acessibilidade em infografias para surdos, propondo uma reflexão sobre este tema a partir na noção de imagem complexa de Català [2011] e da fenomenologia de Merleau-Ponty [1999]. O intuito é discutir a ideia de que o infográfico pode ser percebido não somente pelo olhar, mas por todas as vias corporais.

\section{Infographic, Deaf, Accessibility}

This article deals with infographics accessibility for deaf people, proposing a reflection on this theme from the notion of complex image of Català [2011] and the phenomenology of Merleau-Ponty [1999]. The intention is to discuss the idea that the infographic can be perceived not only by the look, but in all bodily ways.

\section{Introdução}

A pergunta que surge no título deste artigo ("será que os segredo mais secretos pertencem ao mundo visível?") foi realizada por Maria João Ceitil [2001] num belíssimo texto intitulado "Uma história aromática de Bagdage".
Esta publicação questiona o olhar como única maneira de acessar o mundo, de construir saberes. Através de uma narrativa (associada à teoria) sobre um casal que perde o sentido do olfato e a intimidade dos sonhos, a autora aborda o visível, o visual e o pensamento do ponto de vista filosófico. Trata-se de uma crítica a um tipo de pensamento 


\section{$16^{\circ}$ \\ ERGODESIGN USIHC CINAHPA}

que descarta a dimensão carnal e sensível do corpo, ou seja, um pensamento mais subjetivo. Este campo seria um "[...] domínio pantanoso, confuso, escorregadio, ilusório, sobretudo nãocientífico... como se o 'ser científico' fosse sinônimo de qualquer soberania, qualquer superioridade" [CEITIL, 2001, p.45].

Esta autora portuguesa caminha por uma trilha da filosofia, que este trabalho utiliza como inspiração, a partir da visão merleau-pontyana, para levantar questões acerca do mundo da comunicação. $\mathrm{O}$ intuito é abordar a infografia, um recurso comunicativo constituído de imagens, textos e sons (no caso de estarem situadas num ambiente hipermídia). Assim, surgem as questões: como a infografia pode ser apreendida por outras vias além do olhar? E quando voltadas aos surdos, como são percebidas? Como este recurso pode se tornar acessível para os surdos?

Ao iniciar a escrita deste trabalho não há clareza se é possível apresentar respostas para todos estes questionamentos. Assim, o objetivo é propor uma reflexão sobre esses assuntos, apresentando dados coletados durante a realização da tese "Visualização do Conhecimento por meio de narrativas infográficas na web voltadas para surdos em Comunidades de Prática", de autoria de Mariana Lapolli com orientação do professor Tarcísio Vazin da Universidade Federal de Santa Catarina (UFSC) e tutoria do professor José Luis Valero Sancho da Universitat Autònoma de Barcelona (UAB).

Além de Lapolli (2014), a fundamentação teórica desta investigação será pautada pela noção de imagem complexa de Català [2011], pela fenomenologia de Merleau-Ponty [1999] e pelos estudos de Marques [2007] sobre a cultura surda. Assim, o trabalho inicia com a questão das imagens e suas significações, entrando no tema da infografia. Em seguida trata-se do desenvolvimento dessa ferramenta com acessibilidade para surdos, finalizando com uma discussão sobre a maneira dessas pessoas de experienciar/ perceber o mundo. $16^{\circ}$ Ergodesign - Congresso Internacional de Ergonomia e Usabilidade de Interfaces Humano Tecnológica: Produto, Informações Ambientes Construídos e Transporte

$16^{\circ}$ USIHC - Congresso Internacional de Ergonomia e Usabilidade de Interfaces Humano Computador

CINAHPA | 2017 - Congresso Internacional de Ambientes Hipermídia para Aprendizagem.

\section{0 mundo visível}

As imagens estão por todos os lados. Camille Paglia [2014] diz que nossos olhos são inundados por figuras reluzentes e blocos de textos explodindo sobre nós. Os meios de comunicação tiveram um papel central nesta disseminação descomedida de imagens e textos. A infografia se desenvolveu neste panorama.

Os primórdios da infografia remetem às inscrições rupestres nas paredes de cavernas. Se desenvolveu, enquanto narrativa visual, com a aparição de novos suportes e meios. A popularização da internet, nos anos 1990, permitiram que novas características fossem assumidas por este recurso comunicacional. Isto quer dizer que suas versões estáticas (que aparecem em jornais, revistas, livros etc.) ganharam a possibilidade de interatividade, convergência, multimidialidade, multilinearidade etc.

Infografia na web, on-line, multimídia, interativa, digital ou hipermídia são alguns dos termos para designar este tipo de recurso que associa imagens e textos concisos para estruturar e apresentar informações. Contudo, é preciso saber interrogar a efervescência de sintomas provocados pelas imagens, para extrair seus significados [CATALÀ, 2011].

Català [2011, p.49] fala de uma imagem complexa que "[...] se abre em diversas constelações de significado". Essas constelações englobam o real, o imaginário, o simbólico e o ideológico. Assim, "mais do que ver uma imagem, é preciso estabelecer um olhar atento ao seu significado e às emoções, expressões, sensações e percepções evocadas" [LAPOLLI, VANZIN, 2016, p.22].

Desta maneira, a infografia surge diante do olhar carregada de significados, demandando uma mirada complexa, termo utilizado por Català para se referir a um olhar atento e ativo. Este modo de ver, consciente da complexidade dos infográficos, já pode ser implementado pelo infografista, profissional que possui o dever de coletar, produzir e organizar dados e informações, revelando um caminho para o conhecimento. 


\section{$16^{\circ}$ \\ ERGODESIGN USIHC CINAHPA}

No que diz respeito a mirada voltada a um infográfico, a primeira pergunta que aparece na introdução deste trabalho é: como ele pode ser apreendido por outras vias além do olhar? Outros canais perceptivos entram em jogo na busca pela resposta dessa indagação. Cabe aqui a citação de Merleau-Ponty [1999, p. 304]:

Se quero encerrar-me em um de meus sentidos e, por exemplo, me projeto inteiro em meus olhos e abandono-me ao azul do céu, em breve não tenho mais consciência de olhar e, no momento em que queria fazer-me inteiro visão, o céu deixa de ser uma "percepção visual" para tornar-se meu mundo do momento. A experiência sensorial é instável e é estranha à percepção natural que se faz com todo o nosso corpo ao mesmo tempo e abre-se a um mundo intersensorial.

Esta perspectiva de estender para o corpo aquilo que está sendo visualizado corrobora com a afirmativa de Català [2011, p. 19] de que "a visão, em sentido geral, não está relacionada com os olhos. Na verdade podemos dizer que vemos também por meio do corpo [...]”. Este corpo se relaciona com a realidade ao seu entorno. Para Català [2011], o corpo constitui uma ponte entre a representação e o sujeito, que é capaz de tornar o ato perceptivo num processo reflexivo.

Mas tudo isso só pode ser sentido para nós se o considerarmos a partir do momento em que ja temos uma ideia clara do que significa a visão e das relações que ela mantém com o que chamamos de imagem [CATALÀ, 2011, p. 19].

Este é o momento em que as palavras surgem numa tentativa de esclarecimento deste mundo que não é neutro ou objetivo. Carregado de cultura, contexto, imaginário, identidade e individualidade, o intérprete trata de elucidar as experiências que se depreendem dessa visão. Mas será que as infografias abrem espaço para tantas conotações?

Valero Sancho [2001] revela que qualquer elemento gráfico, ilustração ou desenho com certa dose de originalidade, beleza etc., permite obter um valor superior de conotações. Contudo, quando $16^{\circ}$ Ergodesign - Congresso Internacional de Ergonomia e Usabilidade de Interfaces Humano Tecnológica: Produto, Informações Ambientes Construídos e Transporte

$16^{\circ}$ USIHC - Congresso Internacional de Ergonomia e Usabilidade de Interfaces Humano Computador

CINAHPA | 2017 - Congresso Internacional de Ambientes Hipermídia para Aprendizagem.

o documento tem propósitos de divulgação de conhecimentos, esses requisitos estéticos são secundários [VALERO SANCHO, 2015].

A infografia do jornalista espanhol Jaime Serra serve de exemplo de oferta de um valor superior de conotações. Sua veia artística influi na dose de originalidade e beleza que compõem o seu trabalho. Na infografia Oro Verde, publicada no Jornal argentino Clarín, informações sobre o mate são apresentadas com criatividade e domínio de técnicas ilustrativas. O papel utilizado como suporte para esta obra foi especialmente feito a mão com erva-mate moída e, como tinta para colorir as ilustrações, foi usado o próprio chá. Deste modo, um comprometimento estético no desenvolvimento desta peça é revelado.

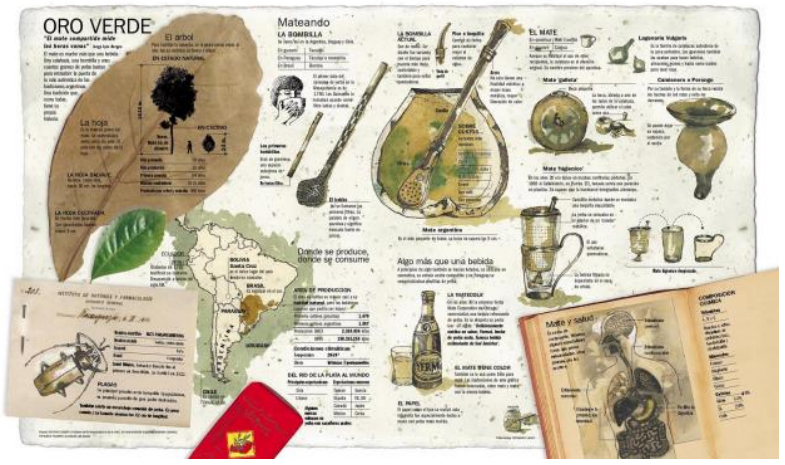

Figura 1: Infográfico Oro Verde de Jaime Serra Fonte:

http://4.bp.blogspot.com/_LCqDL30ndZQ/S6yjEUIMhj I/AAAAAAAAATo/1EwJlyN8kVw/s1600/Mate.jpg

Serra trabalhou no Clarín durante a segunda metade da década de 1990, num período em que ele e sua equipe inspiraram diversos outros profissionais a buscar novas maneiras de se fazer infografia, indo além da ilustração vetorial. Sobre seu processo criativo, Pliger [2012, p.20] declara:

Esse processo de criação inovador para a época ampliava as possibilidades comunicativas dos infográficos, até então utilizados para comunicar informações de uma maneira objetiva, mediante um sistema que buscava reduzir ao máximo a polissemia. Um dos aspectos mais interessantes desses trabalhos era o fato de que o impacto causado pela sua intensa expressividade não comprometia a clareza 


\section{$16^{\circ}$ \\ ERGODESIGN USIHC CINAHPA}

de compreensão das informações representadas. Serra fazia uso deliberado da polissemia para acrescentar significados no processo de comunicação, sem comprometer a transmissão de dados e informações no infográfico [...].

O uso da polissemia ganhou potencia com as novas tecnologias da informação e da comunicação, exigindo não somente um olhar mais atento, mas outros sentidos também, como os ouvidos devido a introdução de sons nas infografias. $\mathrm{O}$ corpo se coloca, neste caso, no intermédio entre o infográfico e o sujeito, a fim de apreender o conhecimento disponibilizado.

\section{0 mundo sem sons}

Dos mais de 190 milhões de brasileiros, 9.722.163 pessoas possuem deficiência auditiva, sendo 347.481 surdos [IBGE, 2010]. Para esta instituição, deficientes auditivos são aqueles que possuem uma diminuição da capacidade de percepção normal dos sons; e surdos aqueles que não possuem resquícios de audição. Há divergências em relação a utilização desses termos entre os diversos autores que abordam a temática. Nesta pesquisa, optou-se por utilizar os termo surdo, dizendo respeito as pessoas que fazem parte da comunidade surda.

Posto isto, e entendendo que, conforme a visão merleau-pontyana, o mundo é percebido por meio dos sentidos e da experiência de vida, colocam-se em pauta as perguntas: como as infografias são percebidas quando voltadas aos surdos? E como este recurso pode se tornar acessível para os surdos?

Frisa-se aqui que acessibilidade, no espaço digital, "consiste em tornar disponível ao usuário, de forma autônoma, toda a informação [...], independentemente de suas características corporais [...]" [TORRES, MAZZONI, ALVES, 2002, p.85].O World Wide Web Consortium (W3C) possui diretrizes de acessibilidade, abrangendo recomendações para os conteúdos web, porém essas diretrizes são bastante generalizadas, uma vez que são voltadas para todo tipo de necessidade especial. $16^{\circ}$ Ergodesign - Congresso Internacional de Ergonomia e Usabilidade de Interfaces Humano Tecnológica: Produto, Informações Ambientes Construídos e Transporte

$16^{\circ}$ USIHC - Congresso Internacional de Ergonomia e Usabilidade de Interfaces Humano Computador

CINAHPA | 2017 - Congresso Internacional de Ambientes Hipermídia para Aprendizagem.

A tese de doutorado de Lapolli [2014] traz indicativos que se aproximam de repostas para as questões colocadas neste item. Em sua pesquisa, a autora desenvolveu três infografias hipermídias (as telas inicias de cada infografia são apresentadas nas figuras 2, 3 e 4) com conteúdos educativos acessíveis para surdos e verificou-as com grupos de pessoas surdas e ouvintes por meio de entrevistas semiestruturadas. Para extrair a opinião dos participantes da pesquisa, definiu-se um recorte do tema a ser debatido, formulando estrategicamente um roteiro da entrevista. Os dados obtidos a partir da transcrição das entrevistas foram analisados por meio da Técnica do Discurso do Sujeito Coletivo - DSC, cujo intuito é reunir conteúdos de depoimentos com sentidos semelhantes, sob a forma de discursos únicos, provocando no leitor um efeito de "coletividade falando" [LEFÈVRE, LEFÈVRE, MARQUES, 2009].

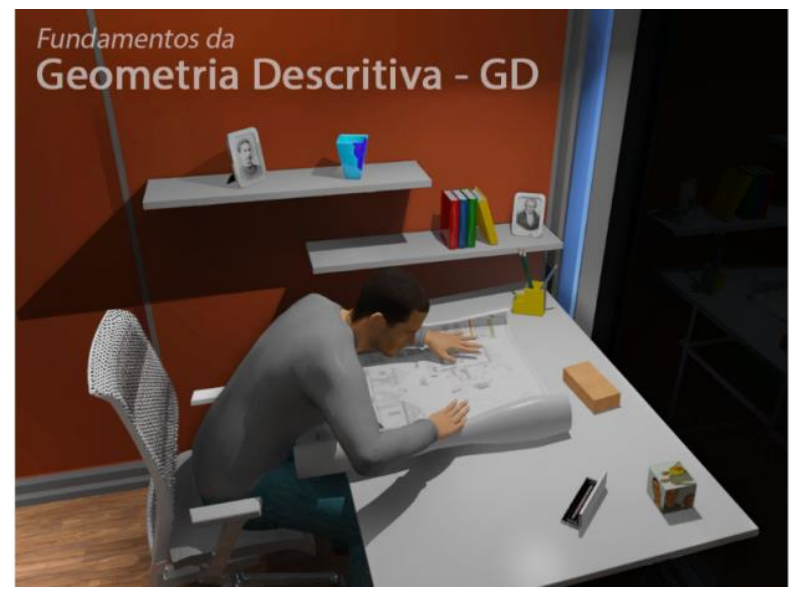

Figura 2: Tela inicial do infográfico 1

Fonte: www.cognitivabrasil.com.br/moobi/mariana 

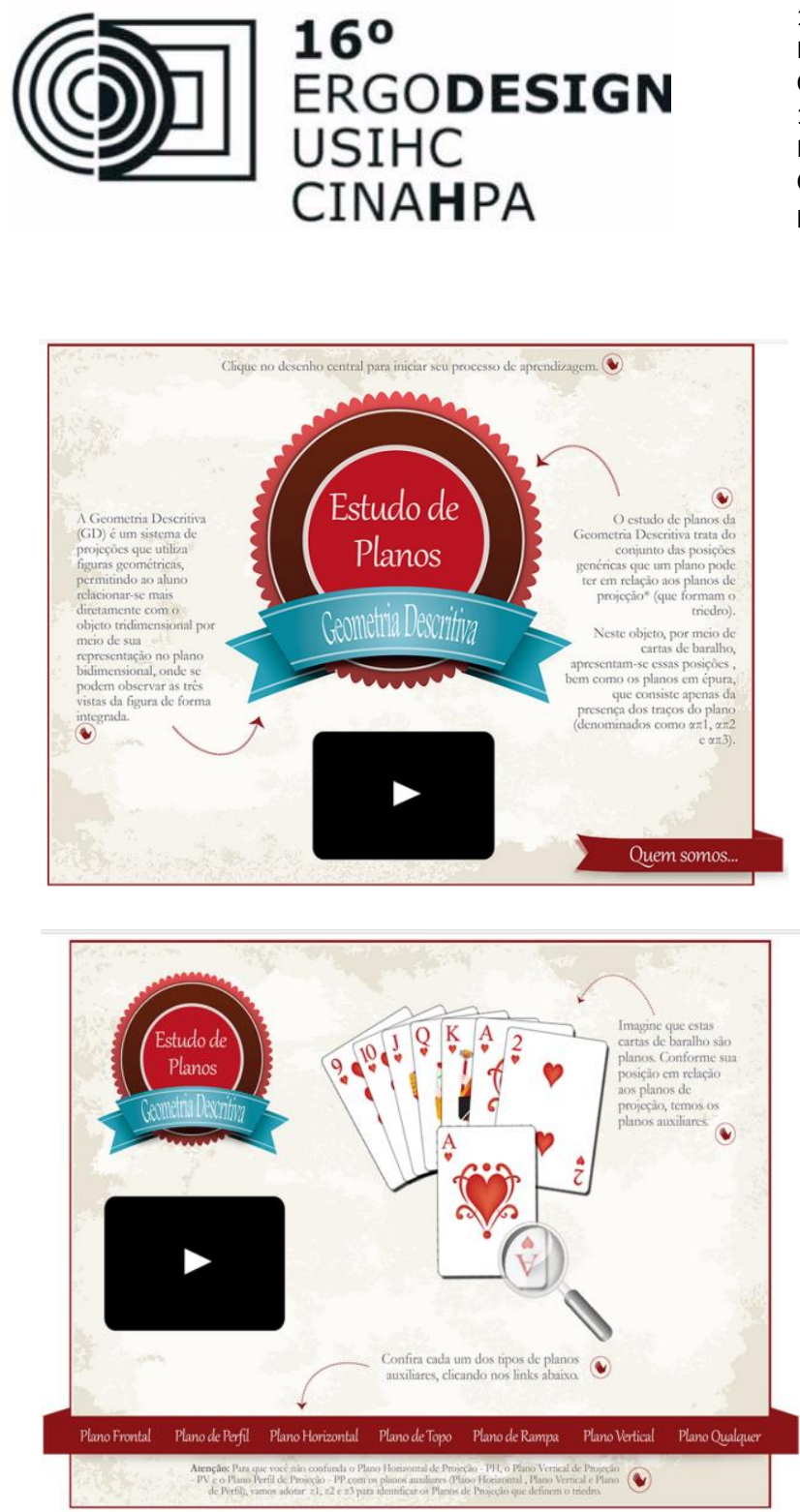

Figura 3: Telas iniciais do infográfico 2

Fonte: cognitivabrasil.com.br/moobi/mariana/mariana2

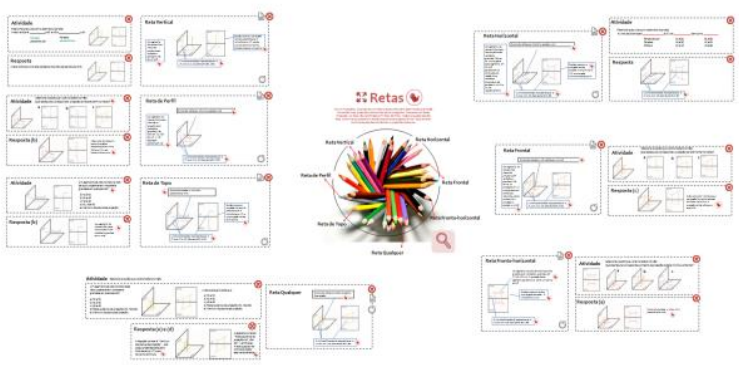

Figura 4: Tela inicial do infográfico 3

Fonte: cognitivabrasil.com.br/moobi/mariana/lapis

Para este artigo, serão descritas algumas passagens que revelam como as infografias em questão foram percebidas pelos participantes da pesquisa. Num primeiro momento, estes agentes disseram gostar do material e que ficaram com vontade de brincar, sendo assim tratava-se de um formato bem provocativo, como descrito neste trecho do DSC: $16^{\circ}$ Ergodesign - Congresso Internacional de Ergonomia e Usabilidade de Interfaces Humano Tecnológica: Produto, Informações Ambientes Construídos e Transporte

$16^{\circ}$ USIHC - Congresso Internacional de Ergonomia e Usabilidade de Interfaces Humano Computador

CINAHPA | 2017 - Congresso Internacional de Ambientes Hipermídia para Aprendizagem.
Eu acho muito interessante o infográfico, principalmente porque você faz escolhas, faz o seu caminho também, você não precisa seguir uma ordem. Você ficou instigado, vai clica e vê como funciona [LAPOLLI, 2014, p.247].

Os participantes da pesquisa elogiaram o uso de imagens, revelando que elas ajudam no entendimento do conteúdo:

Se não tem imagem, só o texto, não entende nem do que está falando. [...] Parece que a gente tem mais atenção, fica mais claro de entender. [...] Melhor o texto curto mesmo. É uma ótima estratégia. Sem dúvida mais imagem e menos textos. A imagem fala por mil palavras, então qualquer imagem auxilia muito mais. Mais do que um textinho. [...] para mim, pareceu bem claro de visualizar, bem intuitivo. Eu achei interessante visualmente. Visualmente eu achei claro. Eu achei as imagens bem claras. Visualmente fácil de perceber. [...] Foi muito visual. Tinha as imagens, tinha texto, tinha LIBRAS. Era colorido. Eu gostei, achei claro, ótimo [LAPOLLI, 2014, p.247-248].

Os entrevistados destacaram positivamente algumas características das infografias, utilizando as seguintes palavras: dinâmico, colorido, chamavam a atenção, criatividade, claro, fácil de entender, equilíbrio, bonitos, organizados, leve. Mas também houveram críticas ao acessar os três trabalhos, como: cansaço, difícil, os desenhos não combinavam, desafio.

Quanto a navegação também houveram opiniões divergentes. Alguns gostaram da liberdade de navegação, outros preferiram momentos em que a prática era mais linear. Sobre isto, nas conclusões de sua tese, Lapolli [2014] destaca a necessidade de haver uma hierarquia no acesso aos links, estando ativos primeiramente aqueles com conteúdos mais simples e, à medida que a complexidade aumenta, novos links devem ser ativados. Ressalta ainda que efeitos (como brilho, zoom, mudança de cor etc.) devem ser usados para indicar onde existe um link. Além disso, coloca que cada tipo de conteúdo tem que possuir um 


\section{$16^{\circ}$ \\ ERGODESIGN USIHC CINAHPA}

efeito diferente.

Desta maneira, mesmo que o ambiente tenha como característica a não linearidade, dando liberdade de escolha para o intérprete, a informação deve ser organizada para que ele não perca nenhum conteúdo e saiba encontrar o que necessita [LAPOLLI, 2014, p.195-196]

Para os surdos, a tradução dos textos em Língua Brasileira de Sinais (LIBRAS) foi bem importante, devido suas dificuldades de compreensão da língua portuguesa. Sobre isto, eles revelam no DSC:

Eu acho que precisa saber que os surdos não conhecem muitas palavras. Alguns surdos conseguem, mas alguns têm muita dificuldade. Por isso que os surdos têm mais atenção para as imagens e não para o português [...]. Os surdos não leem em português como os ouvintes, eles têm dúvidas se é ou não é aquilo. Por isso que é bom a imagem, porque o surdo é visual. [...]. Se tem imagem ligada ao contexto, fica muito mais gostoso, fica muito mais fácil. Até pra comprar um livro. Eu compro livro que tenha imagem. Por isso eu acho importante ter, não desvinculado um do outro. [...] Deixar só imagem, também não acho legal. É bom ter os dois para ter uma informação completa. [...] O surdo é muito visual, então quando ele vê a imagem e vê a LIBRAS ele liga muito melhor. [...]. Para mim da forma como estava lá, o português e a LIBRAS eu acho bom. Dá para comparar, da para ver. Em minha opinião é muito bom, porque fica muito bilíngue, fica bem visual, tem a escrita, então eu acho que fica bom. Porque usa a imagem verbal e a não verbal, as duas juntas [LAPOLLI, 2014, p.257-258].

Ao utilizar textos associados à imagem numa infografia, não se pode esquecer o fato da tipografia ser também uma informação visual. As letras devem ser legíveis, com contraste e fontes adequados, hierarquizadas, devem compor com as imagens etc.

Tudo deve ser elaborado no sentido de dar ênfase às explicações mais importantes, ou seja, ao $16^{\circ}$ Ergodesign - Congresso Internacional de Ergonomia e Usabilidade de Interfaces Humano Tecnológica: Produto, Informações Ambientes Construídos e Transporte

$16^{\circ}$ USIHC - Congresso Internacional de Ergonomia e Usabilidade de Interfaces Humano Computador

CINAHPA | 2017 - Congresso Internacional de Ambientes Hipermídia para Aprendizagem.

conteúdo que se pretende passar. As imagens utilizadas não devem sobrecarregar a carga cognitiva do intérprete, sendo necessário um equilíbrio no seu uso, não poluindo o ambiente. Imagens meramente decorativas que não contribuem para a compreensão do conteúdo não devem ser utilizadas.

Isto não significa que não possa haver um grau de complexidade nas imagens, como visto na definição de Català na introdução deste artigo. Um comprometimento estético e a introdução de imagens complexas, carregadas de conhecimentos, trazem mais possibilidade de conotação e, assim sendo, o desenvolvimento de uma cultura visual crítica.

\section{0 mundo percebido pelo corpo}

Como visto no itens anteriores, a percepção de mundo revela um enfoque no olhar. Contudo, a experiência visual é apenas uma entre as várias vias que um corpo pode adquirir conhecimento, experimentar o mundo [MERLEAU-PONTY, 1999].

Os surdos podem, desta maneira, perceber seu entorno por outras vias que não somente o olhar. Por exemplo, Marques [2007] revela que é capaz de sentir a vibração de um som por meio de suas mãos, pernas e pés, podendo inclusive acompanhar as batidas de uma música com movimentos do corpo.

Tal qual um bailarino, os surdos movimentam seus corpos para comunicarem-se através da LIBRAS:

Posso, ainda, criar um cenário da natureza e com as mãos, o corpo e a expressão, conferir-lhe movimentos como o rio, cuja água escorre em direção a um declive, ou $o$ vento que acaricia as flores e flutua as folhas, e posso ainda dar mais vida a esse cenário inserindo uma ave planando sobre $\mathrm{o}$ anil ou um peixe ao embalo das águas. O corpo está entrelaçado nesse cenário e é parte integrante dele na sua completude; 
$16^{\circ}$ Ergodesign - Congresso Internacional de Ergonomia e Usabilidade de Interfaces Humano Tecnológica: Produto, Informações Ambientes Construídos e Transporte

$16^{\circ}$ USIHC - Congresso Internacional de Ergonomia e Usabilidade de Interfaces Humano Computador

CINAHPA | 2017 - Congresso Internacional de Ambientes Hipermídia para Aprendizagem. neste momento, não é apenas o corpo físico, mas a transposição de um espetáculo que se anuncia [MARQUES, 2007, p.80].

O texto de Marques [2007] propõe uma reflexão sobre as potencialidades do corpo da pessoa surda que, segundo ele, expõe propriedades que as distinguem das pessoas não surdas. Quais sejam: a interpretação visual, o desejo de estar com outro semelhante surdo, o tato mais aguçado, a Língua de Sinais etc.

Essas novas significações corpóreas podem ser consideradas como substâncias primeiras advindas fora de nossa consciência, partindo da construção de novas significações e novas causas em consonância com o mundo percebido [MARQUES, 2007, p.81].

$\mathrm{O}$ autor aproveita este gancho para questionar o termo "deficiente", argumentando que se o corpo tem a capacidade de superar limitações, construindo outras significações "já não se trata de um corpo deficiente, mas de um corpo diferente" [MARQUES, 2007, p.82]. E este corpo não deve ser estereotipado de acordo com a percepção dos não surdos. Deve-se compreender que ele apenas possui uma maneira diferente de perceber e conhecer o mundo a seu redor.

Marques [2007] finaliza seu texto pronunciando que partiu desse conflito para buscar na fenomenologia uma resposta que oferecesse a oportunidade de uma construção e um desenvolvimento possível para os surdos. A proposta é que as pesquisas não tentem corrigir o corpo da pessoa surda, mas sim descubra "[...] novas potencialidades, viabilizando, através da tecnologia, a criação de novas estratégias que atendam às necessidades das pessoas surdas" [MARQUES, 2007, p.85].

\section{Considerações Finais}

O intercâmbio entre corpo e mundo tece significações. Porém, na atualidade, com a grande quantidade de imagens espalhadas por todos os lados, é ponto pacífico que se direcione o foco para as experiências visuais. Ainda mais quando o objeto tratado é um recurso que possui forte apelo nesse sentido, como é o caso do infográfico.

Assim, o primeiro ponto abordado neste artigo foi justamente a questão da imagens e a importância de saber interrogá-las, extraindo seus mais diversos significados. Falou-se em imagem complexa [CATALÀ, 2011] e a exigência de um olhar atento sobre este tipo de representação.

Entendendo que as infografias são carregadas de polissemia, sobretudo quando há um cuidado estético em sua concepção, sua compreensão é afetada pelo desenvolvimento de uma cultura visual. E, mais do que isto, este trabalho buscou frisar a importância do corpo nesta mediação entre a representação e o sujeito, apoiando-se na visão de Merleau-Ponty.

Para tratar da acessibilidade em infografias para surdos, Marques [2007] foi convocado para esta conversa. Este autor utiliza a visão merleupontyana para tratar da maneira diferente dos surdos perceberem o mundo. Isto é relevante, uma vez que por muitos anos, a surdez vem sendo tratada como deficiência. Como se os parâmetros para se relacionar com o mundo fossem validados somente por meio da perspectiva dos ouvintes. Por exemplo, como se uma música só pudesse ser percebida por meio de seu som e não de sua vibração para dar ritmo a uma dança.

No sentido de ilustrar a prática do desenvolvimento de infográficos para surdos, foram citados os três objetos desenvolvidos por Lapolli [2014]. A partir deles, algumas falas emitidas pelos participantes dessa investigação foram apresentadas neste artigo, tornando-se possível extrair recomendações sobre o que é necessário para que um infográfico seja acessível a esse público. Algumas percepções puderam, assim, ser captadas por meio de seus depoimentos.

Mas esta discussão sobre como apreender uma infografia por outras vias além do olhar, principalmente quando voltada para as pessoas com surdez, não se esgota aqui. Nem era esta a pretensão. O intuito é chamar atenção para outras 


\section{$16^{\circ}$ \\ ERGODESIGN USIHC CINAHPA}

maneira de construção de significados, para os interpretes das infografias, que vão além do olhar. Afinal, ela pode ser também apreendida pelos sons ou vibrações, pelo poros, pelos cheiros etc.

Como exposto na narrativa de Ceitil [2001], mencionada na introdução desta publicação, o segredo encontrado em Bagdage estava em tocar e sentir o que nunca se havia sentido, sentir o aroma do corpo do parceiro, ouvir sons murmurados e sorrir. Destarte, a proposta aqui é compreender que o mundo pode ser percebido por todas as vias, de maneira diferente por cada indivíduo, que é levado a mergulhar num mundo subjetivo.

\section{BIBLIOGRAFIA}

CATALÀ DOMÉNECH, J. M. A forma do real. São Paulo: Summus, 2011.

CEITIL, M. J. Uma História aromática em Bagdage. In: Phainomenon. Lisboa: Edições Colibri, 2001, p.37-50.

IBGE. Censo. 2010. Disponível em: <http://www.censo2010.ibge.gov.br/>. Acesso em: 15 jan. 2012.

LAPOLLI, M. Visualização do conhecimento por meio de narrativas infográficas na web voltadas para surdos em comunidades de prática. 2014. 277 f. Tese (Doutorado em Engenharia e Gestão do Conhecimento). Programa de pós-graduação em Engenharia e Gestão do Conhecimento, Universidade Federal de Santa Catarina (UFSC). Florianópolis, 2014.

LAPOLLI, M.; VANZIN, T. Infografia na era da cultura visual. Florianópolis: Pandion, 2016.

LEFEVRE, F.; LEFEVRE, A. M. C. MARQUES, M. C. da C. Discurso do sujeito coletivo, complexidade e auto-organização. Ciênc. saúde coletiva, Rio de Janeiro, v. 14, n. 4, Aug. 2009. Disponível em

$<$ http://www.scielo.br/scielo.php?script=sci_arttext \&pid=S1413-

$81232009000400025 \& \operatorname{lng}=$ en\&nrm=iso $>$. Acesso em: 28 fev. 2017. $16^{\circ}$ Ergodesign - Congresso Internacional de Ergonomia e Usabilidade de Interfaces Humano Tecnológica: Produto, Informações Ambientes Construídos e Transporte

$16^{\circ}$ USIHC - Congresso Internacional de Ergonomia e Usabilidade de Interfaces Humano Computador

CINAHPA | 2017 - Congresso Internacional de Ambientes Hipermídia para Aprendizagem.

MARQUES, R. R. A percepção do corpo próprio e o "ser surdo". Ponto de Vista, Florianópolis, n. 9, p. $75-85,2007$

MERLEAU-PONTY, M. Fenomenologia da percepção. $2^{\mathrm{a}}$ ed. São Paulo: Martins Fontes, 1999.

Oro Verde. Disponível em:

<http://4.bp.blogspot.com/_LCqDL30ndZQ/S6yjE UIMhjI/AAAAAAAAATo/1EwJlyN8kVw/s1600/ Mate.jpg >. Acesso em: 01 mar. 2017.

PAGLIA, C. Imagens Cintilantes: uma viagem através da arte desde o Egito a Star Wars. Rio de Janeiro: Apicuri, 2014.

PLIGER, M. A Construção da Expressividade na infografia: um estudo de criações de Jaime Serra. Dissertação (Mestrado em Comunicação e Semiótica) - Pontifícia Universidade Católica de São Paulo, São Paulo, 2012.

Tela inicial do infográfico 1. Disponível em: <www.cognitivabrasil.com.br/moobi/mariana>. Acesso em: 01 mar. 2017.

Telas iniciais do infográfico 2. Disponível em: <www.cognitivabrasil.com.br/moobi/mariana>. Acesso em: 01 mar. 2017.

Tela inicial do infográfico 3. Disponível em: <www.cognitivabrasil.com.br/moobi/mariana>. Acesso em: 01 mar. 2017.

TORRES, E. F.; MAZZONI, A. A.; ALVES, J. B. da M. A acessibilidade à informação no espaço digital. Ci. Inf., Brasília, v. 31, n. 3, p. 83-91, set./dez. 2002. Disponível em: 〈www.scielo.br/pdf/ci/v31n3/a09v31n3.pdf〉. Acesso em: 28 fev. 2017.

VALERO SANCHO, J. L. La infografia: técnicas, análisis y usos periodísticos. Bellaterra: Universitat Autònoma de Barcelona, Servei de Publicacions, 2001.

Entrevista semiestruturada. Entrevista concedida a Mariana Lapolli, 01 out. 2015.
Realização:

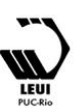




\section{$16^{\circ}$}

ERGODESIGN

USIHC CINAHPA $16^{\circ}$ Ergodesign - Congresso Internacional de Ergonomia e Usabilidade de Interfaces Humano Tecnológica: Produto, Informações Ambientes Construídos e Transporte

$16^{\circ}$ USIHC - Congresso Internacional de Ergonomia e Usabilidade de Interfaces Humano Computador

CINAHPA | 2017 - Congresso Internacional de Ambientes Hipermídia para Aprendizagem.

\section{Agradecimentos}

À CAPES pelo apoio nas pesquisas desenvolvidas durante o doutorado e pós-doutorado. Aos participantes da pesquisa cujo resultados são apresentados neste artigo. Ao grupo de pesquisa WebGD Acessível. 